\title{
Tracing the influence of Fe sources in the North Pacific using Fe isotopes (preliminary results from GP15)
}

SIEBER, M. ${ }^{*}$, LANNING, N. T. ${ }^{2}$, FITZSIMMONS, J. N. ${ }^{2}$, Weiss, G. ${ }^{3}$, HATTA, M. ${ }^{3}$, JOHN, S. ${ }^{4}$, CONWAY, T. M. ${ }^{1,5}$

${ }^{1}$ College of Marine Science, University of South Florida, St Petersburg, FL, USA.

${ }^{2}$ Dept, of Oceanography, Texas A \& M University, College Station, TX, USA.

${ }^{3}$ Dept of Oceanography,University of Hawaii at Manoa, Honolulu, HI, USA.

${ }^{4}$ Department of Earth Sciences, University of Southern California, Los Angeles, CA. USA.

${ }^{5}$ School of Geoscience, Univerity of South Florida, St Petersburg, FL, USA.

*correspondence: sieberm@mail.usf.edu

The dissolved micronutrient iron $(\mathrm{Fe})$ limits growth of phytoplankton over much of the surface oceans, especially in high-nutrient low-chlorophyll regions (HNLC) such as the subarctic North Pacific [1]. Despite the recent expansion in dissolved $\mathrm{Fe}$ concentration data from the GEOTRACES program [2], measurements in the North Pacific are still scarce, and the pathways by which Fe is supplied to HNLC waters remain largely unkown. Dissolved stable isotope ratios of $\mathrm{Fe}\left(\delta^{56} \mathrm{Fe}\right)$ can help identifying the key $\mathrm{Fe}$ sources and inform understanding of their influence on phytoplankton ecology in the chronically Fe-starved surface waters.

Here, we present water-column profiles of dissolved $\mathrm{Fe}$ and $\delta^{56} \mathrm{Fe}$ from the subarctic North Pacific, using samples collected from a recent GEOTRACES transect along $152^{\circ} \mathrm{W}$ (GP15). The subarctic North Pacific is influenced by both subarctic and subtropical waters from the western Pacific via the North Pacific Current, and waters from the continental shelf via the Alaskan Gyre. Our data highlight the importance of sedimentary $\mathrm{Fe}$ sources, which release iron via reductive and non-reductive dissolution. Our section shows a shallow plume (above $500 \mathrm{~m}$ ) of high $\mathrm{Fe}$ concentrations originating on the shelf, and a deeper Fe plume (1000 to $2500 \mathrm{~m})$ occuring on the steeper slope. While the extent of the shallow plume is limited to waters near the shelf, the deeper plume extends far south, carrying a low $\delta^{56} \mathrm{Fe}$ signature into the waters of the subarctic North Pacific and equatorward through the deep North Pacific OMZ [3]. Both the depth range and the difference in the extent of the two plumes are similar to recent observations in the equatorial Pacific [4].

[1] Martin et al., Deep-Sea Res. 36, 649-680 (1989).

[2] Schlitzer et al., Chem. Geol. 493. 210-223 (2018).

[3] Conway \& John, GCA 148, 269-283 (2015).

[4] John et al., Mar. Chem. 201, 66-76 (2018). 